ORIGINAL ARTICLE

\title{
Urinary mercury concentrations associated with dental restorations in adult women aged 16-49 years: United States, 1999-2000
}

\author{
B A Dye, S E Schober, C F Dillon, R L Jones, C Fryar, M McDowell, T H Sinks
}

Occup Environ Med 2005;62:368-375. doi: 10.1136/oem.2004.016832

See end of article for authors' affiliations

.....................

Correspondence to: Dr B Dye, CDC/NCHS/ NHANES Program, 3311 Toledo Road, RM 4416, Hyattsville, MD 20782, USA; bfd1@cdc.gov

Accepted

19 November 2004

\begin{abstract}
Background: Mercury amalgam dental restorations have been used by dentists since the mid 19th century and issues on safety continue to be periodically debated within the scientific and public health communities. Previous studies have reported a positive association between urine mercury levels and the number of dental amalgams, but this relation has never been described in a nationally representative sample in the United States.

Aims and Methods: Using household interview, dietary interview, dental examination, and laboratory data from the 1999-2000 National Health and Nutrition Examination Survey (NHANES), the association between mercury concentrations and dental restorations was examined in US women of reproductive age. Results: In women of childbearing age, approximately $13 \%$ of all posterior dental surfaces were restored with amalgams and the average urinary mercury level in women was low $(1.34 \mu \mathrm{g} / \mathrm{l})$. It is estimated that an increase of $1.8 \mu \mathrm{g} / \mathrm{l}$ in the log transformed values for mercury in urine would occur for each 10 dental surfaces restored with amalgam.

Conclusions: Although the findings do not address the important issues of adverse health effects at low thresholds of mercury exposure, they do provide important reference data that should contribute significantly to the ongoing scientific and public health policy debate on the use of dental amalgams in the USA.
\end{abstract}

Mercury exists in several oxidation states: metallic or elemental mercury $\left(\mathrm{Hg}^{0}\right)$, inorganic mercury ( $\mathrm{IHg}$ : including $\mathrm{Hg}^{+}$(mercurous salts) and $\mathrm{Hg}^{++}$(mercuric salts)), and organic mercury (principally methylmercury (MeHg), but also ethyl-, phenylmercury, and others). Mercury absorption and relative toxicity depend on its chemical form. All forms of mercury are neurotoxic depending on dose, but $\mathrm{MeHg}$ has the greatest potential neurotoxicity, with $\mathrm{Hg}^{++}$less so. Both $\mathrm{Hg}^{0}$ and $\mathrm{Hg}^{++}$are nephrotoxic. Vapour inhalation is the principal route of exposure to elemental mercury, which is then oxidised to $\mathrm{Hg}^{++}$and excreted in the urine.

It is estimated that the majority of the daily intake of mercury compounds is $\mathrm{MeHg}$ derived from dietary sources (contaminated fish) and to a lesser extent, elemental mercury from mercury vapour in dental amalgams. ${ }^{78}$ In 1999, the Agency for Toxic Substances and Disease Registry issued a public health statement on mercury, stating that dental amalgam was a major source of elemental mercury exposure in the general population. Other common sources of elemental mercury exposure are certain occupations, household products such as batteries, thermostats, fluorescent lights, and thermometers, and also contaminated air near medical incinerators and coal burning power plants. ${ }^{9}$ Approximately $95 \%$ of $\mathrm{MeHg}$ in fish is absorbed by the gastrointestinal tract $^{10}$ and $\mathrm{MeHg}$ has a biological half-life of about 70 days. ${ }^{11}$ Total blood mercury is a principal biomarker for $\mathrm{MeHg}$ exposure but it is thought that a small amount of blood MeHg is metabolised to $\mathrm{IHg}$ and excreted in the urine. ${ }^{8}$

Historically, the composition of dental amalgam has changed very little with the mixture containing copper, tin, silver, and up to $50 \%$ of elemental mercury by weight.

Abbreviations: 1999-2000 NHANES, 1999-2000 National Health and Nutrition Examination Survey; $\mathrm{Hg}$, inorganic mercury; $\mathrm{MeHg}$, methylmercury 


\section{Main messages}

- Accurate reference data for mercury exposure from dental amalgams is not available for the general population; however, the 1999-2000 National Health and Nutrition Examination Survey provides representative US data on mercury exposure and dental care for women of reproductive age.

- Among US adult women, approximately $13 \%$ of all posterior dental surfaces were restored with amalgams.

- It is estimated that a urine mercury increase of $1.8 \mu \mathrm{g} /$ $g$ urinary creatinine would occur for each additional 10 dental surfaces restored with amalgam.

- This study provides important reference data pertinent to the ongoing scientific and public health policy debate on the use of dental amalgams.

Mercury vapour can be released from amalgam restorations during periods of chewing, ${ }^{12-14}$ nocturnal bruxism, ${ }^{15}$ and consumer teeth whitening products. ${ }^{16}{ }^{17}$ About $30-50 \%$ of the generated mercury vapour is inhaled, with $80 \%$ absorbed via the lungs and distributed to the brain and kidneys. ${ }^{7} 1819$ Elimination is via the urine and faeces, ${ }^{20-22}$ and up to $40 \%$ of the absorbed mercury is eliminated within 30 days following vapour exposure. ${ }^{23}$ It is estimated that for every 10 dental amalgam surfaces, mercury urinary concentrations will increase by $1 \mu \mathrm{g} / \mathrm{l}^{24}$

Accurate national estimates of IHg body burden among persons with dental amalgams are essential for any population based risk assessment. Except for one large retrospective cohort study involving military men, ${ }^{24}$ most prior US research on amalgam restorations and mercury levels has been clinical studies involving limited populations. The aim of our study is twofold: (1) to describe the relation between dental restorations and urine mercury concentrations using a nationally representative sample of women of childbearing age; and (2) to produce models that improve our understanding of risk indicators for increased urinary mercury for women in the USA.

\section{METHODS}

\section{Study population}

We used data from the 1999-2000 National Health and Nutrition Examination Survey (NHANES), a representative sample of the civilian, non-institutionalised population in the USA. The 1999-2000 NHANES over sampled persons 12-19 years of age, persons 60 years and older, non-Hispanic blacks, and Mexican Americans. Furthermore, all women who indicated that they were pregnant at the time of the screening interview were selected into the sample, and low income white persons were over sampled in 2000. An institutional review board approved the 1999-2000 NHANES protocols and informed consent was obtained from all participants, with parents or guardians providing consent for individuals less than 18 years of age. The NHANES is conducted by the National Center for Health Statistics of the Centers for Disease Control and Prevention. Information for accessing the 1999-2000 NHANES data, technical notes, and guidelines used can be found at: http://www.cdc.gov/nchs/ about/major/nhanes/NHANES99_00.htm.

The 1999-2000 NHANES assessed mercury exposure in women 16-49 years old. There were 1944 women aged 16-49 years old who completed a home interview. We excluded 125 women who did not participate in the examination at a mobile examination centre and 71 women who lacked urine mercury or creatinine data. We excluded 107 participants lacking information on dental restorations and 12 women who were edentulous. Three individuals with extremely high levels of urine, blood, and hair mercury were excluded because it was unlikely that their mercury exposure was related to dental amalgam. The final analytical study group was 1626 persons.

\section{Mercury}

Urine specimens were analysed by flow injection cold vapour atomic absorption by the Division of Laboratory Sciences at CDC's National Center for Environmental Health. ${ }^{25}$ The limit of detection for urine mercury was $0.14 \mu \mathrm{g} / \mathrm{l}$. Mercury was measured by the Perkin-Elmer Flow Injection Mercury System (FIMS-400) spectrometer. The coefficient of variation for urine mercury during the testing period was $10 \%$ or less. Automated cold vapour atomic absorption spectrophotometry was used to analyse whole blood specimens for inorganic and total mercury. Details of these methods have been previously described. ${ }^{26}$

\section{Dental restorations}

The dental examinations were conducted in the mobile examination centre (MEC) by trained dentists who were periodically calibrated by the survey's expert dental examiner (author). Inter-rater reliability for coronal dental caries and restorations was excellent (mean kappa scores for each examiner was 0.96). To evaluate for intra-rater reliability, dental examiners performed a second examination at a later date on approximately $5 \%$ of the sample (mean kappa scores for examiners ranged from 0.93 to 0.94). Because the 19992000 NHANES oral health protocols did not assess for the

Table 1 The sample size (n), percent prevalence, and standard error (SE) for dentate women aged 16-49 years by selected characteristics: United States, 1999-2000

\begin{tabular}{|c|c|c|}
\hline Characteristic & $\mathbf{n}$ & $\%$ (SE) \\
\hline \multicolumn{3}{|l|}{ Age } \\
\hline $35-49$ years & 499 & $45.4(2.12)$ \\
\hline $20-34$ years & 627 & 44.1 (1.97) \\
\hline $16-19$ years & 500 & $10.6(0.71)$ \\
\hline \multicolumn{3}{|l|}{ Race/ethnicity } \\
\hline Non-Hispanic black & 339 & $11.8(0.67)$ \\
\hline Mexican Americans & 553 & $7.4(0.25)$ \\
\hline Non-Hispanic white & 551 & $65.4(2.76)$ \\
\hline Other & 183 & $15.4(2.91)$ \\
\hline \multicolumn{3}{|l|}{ Pregnant } \\
\hline Yes & 280 & $7.6(0.83)$ \\
\hline No & 1344 & $92.4(0.83)$ \\
\hline \multicolumn{3}{|l|}{ Education* } \\
\hline Did not complete high school & 306 & $16.3(1.40)$ \\
\hline Completed high school & 261 & $24.9(2.01)$ \\
\hline Some college & 556 & $58.8(2.48)$ \\
\hline \multicolumn{3}{|l|}{ Cotinine smoking statust } \\
\hline Smoker & 288 & $25.7(2.18)$ \\
\hline Non-smoker & 1229 & $74.3(2.18)$ \\
\hline \multicolumn{3}{|l|}{ Alcohol consumption* } \\
\hline Moderate/heavy drinker & 40 & $5.8(1.26)$ \\
\hline Light drinker & 377 & $41.3(2.76)$ \\
\hline Abstainer & 654 & $52.9(3.27)$ \\
\hline \multicolumn{3}{|c|}{$\begin{array}{l}\text { Fish and/or shellfish consumption in past } \\
30 \text { days }\end{array}$} \\
\hline Yes & 1166 & 78.1 (1.97) \\
\hline No & 409 & $21.9(1.97)$ \\
\hline \multicolumn{3}{|l|}{ Had a dental visit past 12 months } \\
\hline Yes & 1004 & $70.8(1.84)$ \\
\hline No & 619 & $29.2(1.84)$ \\
\hline \multicolumn{3}{|c|}{$\begin{array}{l}n=1626 . \\
\text { *Information for education and alcohol available only on } 20-49 \text { year } \\
\text { olds. } \\
\dagger A \text { smoker is defined as having a cotinine level of } 10 \mathrm{ng} / \mathrm{ml} \text { or higher. }\end{array}$} \\
\hline
\end{tabular}


material composition of dental restorations, we derived the dental amalgam information by two methods: by the number of dental surfaces with restorations and by the extent a participant had dental surfaces restored.

We derived amalgam restorations by counting the number of surfaces of posterior teeth (that is, molars and premolars) with dental restorations. Each posterior tooth has five coronal surfaces: mesial (the front facing interproximal side), occlusal (the chewing area of a tooth), distal (the interproximal side towards the tonsils/pharynx), buccal (the cheek side), and lingual (the tongue side). We also derived the number of occlusal surfaces restored with dental amalgam. If a tooth had all five dental surfaces restored, we assumed that those surfaces were restored with a fabricated dental crown and we excluded those surfaces from the amalgam derivation. The extent of amalgam restored surfaces was calculated by summing the derived surfaces, dividing by the number of dental surfaces evaluated, and multiplying by 100 .

\section{Covariates}

Demographic and health behaviour data were obtained from a home interview questionnaire and an MEC interview. Race/ ethnicity was categorised as non-Hispanic black, Mexican American, non-Hispanic white, and "other". Persons identified as "other" were included in the total population estimates but not in the regression analyses. Educational attainment was categorised as having some college education, completing high school, or not completing high school. Using guidelines established by the National Institute on Alcohol Abuse and Alcoholism, an individual's reported average alcohol consumption over the past 12 months was categorised as moderate or heavy drinker, light drinker, or abstainer. ${ }^{27}$ Information for both education and alcohol consumption was available only for persons 20 years of age or older when we conducted our study. Persons with a serum cotinine level of $10 \mathrm{ng} / \mathrm{ml}$ or higher were classified as current smokers.

Recent dental care utilisation was dichotomised as either having a dental visit in the past 12 months or not. Fish and shellfish information was obtained from a MEC dietary interview. Following the 24-hour dietary recall, respondents were queried regarding consumption of various species of fish or shellfish during the past 30 days. Individuals were grouped into either having consumed any fish and/or shellfish within the past 30 days or not. Age was analysed in 16-19, 20-34, and 35-49 year old age groups. Pregnancy information was obtained from self-report and MEC pregnancy test results.

We used information on lean skeletal muscle mass, fasting, and urine creatinine to correct for urine dilution effects as part of the modelling process and is detailed further in the Discussion section. Lean skeletal muscle mass $(\mathrm{kg})$ was estimated with a validated prediction equation. ${ }^{28}$ The reported number of whole hours since food or drink was last consumed was used to determine fasting status. Fasting was used as a discrete variable and ranged from 0-46 hours. Urine creatinine levels $(\mathrm{mg} / \mathrm{dl})$ were measured with a Beckman Synchron CX3 Clinical Analyser which uses the Jaffè rate reaction. ${ }^{29}$ We used creatinine in urine as a continuous variable for this analysis. In the medical literature, both unadjusted and creatinine corrected urinary mercury values are commonly reported. We include both approaches in our results to allow for comparisons with other studies in the literature.

\section{Data analysis}

All statistical analyses were performed with SUDAAN software (Version 8.0; RTI, Research Triangle Park, NC) and SAS software (Version 8.02; SAS Institute Inc., Cary, NC). We used sample weights to account for the unequal probability of selection and non-response to the study to produce estimates, regression coefficients, and related standard errors. Standard errors were calculated in SUDAAN using the delete 1 jackknife method. The mercury geometric means were obtained with the GEOMETRIC option in SUDAAN and standard deviations were calculated in SAS using the algorithm described in the Appendix. Because mercury was not normally distributed in blood or urine, we used the natural log transformation. Weighted Pearson correlation coefficients and related $\mathrm{p}$ values were calculated in SAS.

Linear regression models were used to estimate unadjusted and adjusted coefficients and related standard errors with $\mathrm{p}<0.05$ considered statistically significant. The log transformation of urine mercury and creatinine corrected urinary mercury were used as dependent variables. All independent variables were modelled as previously described; regressions were performed separately for the total number of derived amalgam dental restorations and the extent of amalgam restorations. We used non-automated stepwise regression modelling to assess the relation between the covariates. Parsimonious models were determined by covariate exclusion with criteria for inclusion set at $p<0.05$ using the Wald Fstatistic. We assessed for potential interactions throughout the modelling process but no significant interactions were found.

\section{RESULTS}

Table 1 presents the sample size and distribution by selected characteristics for women 16-49 years of age. More than 70\% had reported a dental visit within the past 12 months, $25.7 \%$ were smokers, and nearly $78 \%$ had consumed some fish and/ or shellfish in the past 30 days. Table 2 shows the mean mercury concentrations for this study group. The urinary mercury geometric mean for all women was $0.72 \mu \mathrm{g} / \mathrm{l}$ and the arithmetic mean was $1.34 \mu \mathrm{g} / \mathrm{l}$. The creatinine corrected urinary mercury geometric and arithmetic means was $1.10 \mu \mathrm{g} / \mathrm{g}$ and $0.71 \mu \mathrm{g} / \mathrm{g}$ respectively.

The mean number of posterior dental surfaces for women aged 16-49 years in the USA was 71.6 with 12.3 surfaces restored (table 3 ). We estimate that 8.7 posterior surfaces and 4.9 occlusal surfaces were amalgam dental restorations and $12.4 \%$ of all posterior dental surfaces were restored with dental amalgams. Younger women, non-smokers, and those with some college education had a greater number of teeth. Women 35-49 years old, non-Hispanic whites, and persons who had a dental visit within the past 12 months had a greater percentage of dental surfaces restored with dental amalgam. Non-Hispanic whites, non-smokers, those who have consumed fish and/or shellfish in the past 30 days, and persons who had a dental visit within the past 12 months had more posterior dental amalgam restorations.

Table 4 shows correlations between mercury concentrations and dental characteristics. All correlations for dental amalgam exposure were statistically significant for either mercury in urine or creatinine corrected mercury urinary mercury on both the original and log scales. The Pearson correlation coefficients were 0.321 and 0.340 respectively for the extent of amalgam exposure and the number of amalgam dental surfaces for mercury in urine on the non-transformed scale. The correlations between the extent of amalgam exposure and the number of amalgam dental surfaces for creatinine corrected urinary mercury on the log scale were 0.546 and 0.579 .

Table 5 presents results from linear regression models for log transformed urine mercury and creatinine corrected urine mercury. Unadjusted regression models show that urine mercury levels were significantly associated $(p<0.05)$ with being 20-34 years old, non-Hispanic black, smoking, consuming fish and/or shellfish in the past 30 days, higher 
Table 2 The number, mean, and related standard deviation (SD) for mercury $(\mathrm{Hg})$ concentrations by selected characteristics for dentate women aged 16-49 years: United States, 1999-2000

\begin{tabular}{|c|c|c|c|c|c|c|c|c|}
\hline \multirow[b]{2}{*}{ Characteristic } & \multirow[b]{2}{*}{$\mathbf{n}$} & \multicolumn{2}{|c|}{ Total blood Hg } & \multirow[b]{2}{*}{$\mathbf{n}$} & \multicolumn{2}{|l|}{ Urine $\mathrm{Hg} \S$} & \multicolumn{2}{|c|}{ Creatinine adjusted $\mathrm{Hg} \rrbracket$} \\
\hline & & $\begin{array}{l}\text { Arithmetic } \\
\text { Mean (SD) }\end{array}$ & $\begin{array}{l}\text { Geometric } \\
\text { Mean (SD) }\end{array}$ & & $\begin{array}{l}\text { Arithmetic } \\
\text { Mean (SD) }\end{array}$ & $\begin{array}{l}\text { Geometric } \\
\text { Mean (SD) }\end{array}$ & $\begin{array}{l}\text { Arithmetic } \\
\text { Mean (SD) }\end{array}$ & $\begin{array}{l}\text { Geometric } \\
\text { Mean (SD) }\end{array}$ \\
\hline Total & 1566 & 2.02 (3.03) & $1.04(1.15)$ & 1626 & 1.34 (1.77) & $0.72(1.14)$ & $1.10(1.13)$ & $0.71(0.96)$ \\
\hline \multicolumn{9}{|l|}{ Age } \\
\hline $35-49$ years & 481 & $2.29(3.36)$ & $1.26(1.10)$ & 499 & $1.36(1.76)$ & $0.75(1.13)$ & $1.25(1.16)$ & $0.87(0.91)$ \\
\hline $20-34$ years & 602 & $1.94(2.83)$ & $0.96(1.17)$ & 627 & $1.35(1.76)$ & $0.73(1.14)$ & $1.00(1.08)$ & $0.64(0.95)$ \\
\hline $16-19$ years & 483 & $1.15(2.05)$ & $0.60(1.00)$ & 500 & $1.18(1.86)$ & $0.61(1.13)$ & $0.83(1.18)$ & $0.46(1.04)$ \\
\hline \multicolumn{9}{|l|}{ Race/ethnicity } \\
\hline Non-Hispanic black & 323 & $2.16(2.58)$ & $1.32(1.03)$ & 339 & $1.94(2.50)$ & $1.03(1.16)$ & $1.12(1.51)$ & $0.65(1.03)$ \\
\hline Mexican American & 537 & $1.29(1.70)$ & $0.81(0.96)$ & 553 & $1.47(2.22)$ & $0.71(1.21)$ & $1.14(1.42)$ & $0.66(1.05)$ \\
\hline Non-Hispanic white & 529 & $1.89(2.60)$ & $0.99(1.14)$ & 551 & $1.20(1.42)$ & $0.68(1.10)$ & $1.08(1.02)$ & $0.72(0.95)$ \\
\hline \multicolumn{9}{|l|}{ Pregnant } \\
\hline Yes & 269 & $1.78(2.34)$ & $0.93(1.18)$ & 280 & $1.28(1.52)$ & $0.77(1.05)$ & $1.20(1.09)$ & $0.79(0.97)$ \\
\hline No & 1295 & $2.04(3.08)$ & $1.05(1.15)$ & 1344 & $1.34(1.79)$ & $0.72(1.14)$ & $1.09(1.14)$ & $0.71(0.96)$ \\
\hline \multicolumn{9}{|l|}{ Education* } \\
\hline Did not complete high school & 294 & $2.05(3.06)$ & $1.03(1.13)$ & 306 & $1.50(2.36)$ & $0.69(1.24)$ & $1.08(1.54)$ & $0.61(1.04)$ \\
\hline Completed high school & 249 & $1.49(1.80)$ & $0.88(1.04)$ & 261 & $1.21(1.53)$ & $0.66(1.13)$ & $1.02(1.00)$ & $0.67(0.97)$ \\
\hline Some college & 537 & $2.39(3.51)$ & $1.23(1.17)$ & 556 & $1.37(1.66)$ & $0.78(1.11)$ & $1.19(1.03)$ & $0.83(0.89)$ \\
\hline \multicolumn{9}{|l|}{ Cotinine smoking status $\dagger$} \\
\hline Smoker & 288 & $1.56(3.49)$ & $0.81(1.04)$ & 288 & $0.98(1.31)$ & $0.56(1.06)$ & $0.83(1.03)$ & $0.53(0.94)$ \\
\hline Non-smoker & 1228 & $2.16(2.84)$ & $1.12(1.18)$ & 1229 & $1.45(1.91)$ & $0.78(1.16)$ & $1.19(1.17)$ & $0.79(0.95)$ \\
\hline \multicolumn{9}{|l|}{ Alcohol consumption* } \\
\hline Moderate/heavy drinker & 40 & $3.10(3.41)$ & $1.72(1.15)$ & 40 & $1.14(1.11)$ & $0.74(1.04)$ & $1.20(0.94)$ & $0.88(0.83)$ \\
\hline Light drinker & 363 & $2.54(3.69)$ & $1.37(1.13)$ & 377 & $1.23(1.73)$ & $0.67(1.11)$ & $1.09(1.11)$ & $0.71(0.95)$ \\
\hline Abstainer & 635 & $1.63(2.33)$ & $0.88(1.09)$ & 654 & $1.48(1.81)$ & $0.80(1.17)$ & $1.16(1.11)$ & $0.77(0.95)$ \\
\hline \multicolumn{9}{|l|}{$\begin{array}{l}\text { Fish and/or shellfish } \\
\text { consumption in past } 30 \text { days }\end{array}$} \\
\hline Yes & 1124 & 2.37 (3.29) & 1.31 (1.09) & 1166 & $1.43(1.84)$ & $0.80(1.11)$ & $1.17(1.11)$ & $0.80(0.91)$ \\
\hline No & 398 & $0.67(0.77)$ & $0.44(0.90)$ & 409 & $1.07(1.46)$ & $0.54(1.19)$ & $0.86(1.09)$ & $0.50(1.04)$ \\
\hline \multicolumn{9}{|l|}{$\begin{array}{l}\text { Had a dental visit past } \\
12 \text { months }\end{array}$} \\
\hline Yes & 964 & $2.22(3.38)$ & $1.09(1.20)$ & 1004 & $1.37(1.81)$ & $0.75(1.13)$ & $1.15(1.13)$ & $0.77(0.94)$ \\
\hline No & 600 & $1.52(1.87)$ & $0.92(1.01)$ & 619 & $1.25(1.67)$ & $0.66(1.15)$ & $0.96(1.12)$ & $0.59(0.99)$ \\
\hline
\end{tabular}

Corrected Standard Deviation (SD) presented.

Urine $\mathrm{Hg}$ and creatinine adjusted values, $\mathrm{n}=1626$.

Total $\mathrm{Hg}$ in blood, $\mathrm{n}=1566$.

*Information for Education and Alcohol available only on 20-49 year olds.

†A smoker is defined as having a cotinine level of $10 \mathrm{ng} / \mathrm{ml}$ or higher.

†Total mercury in blood ( $\mu \mathrm{g} / \mathrm{l})$.

§Urine mercury ( $\mu \mathrm{g} / \mathrm{l})$.

- Creatinine corrected urine $(\mu \mathrm{g} / \mathrm{g})$.

total blood mercury concentrations, and an increasing number of dental amalgam surfaces. In a multivariate linear model identifying the most parsimonious covariates when the exposure variable was the number of dental amalgam surfaces, only age, race/ethnicity, total mercury in blood, and the number of dental amalgam surfaces were significantly associated with log transformed urine mercury levels (model 1 ). The $R^{2}$ for model 1 was 0.3183 . In a separate analysis (not shown) we found no relation between general employment status (that is, working versus not working) and mercury concentrations in urine.

Unadjusted regression models show that creatinine corrected urine mercury levels were significantly associated $(p<0.05$ ) with age, lower educational attainment, smoking, having a dental visit within the past 12 months, consuming fish and/or shellfish in the past 30 days, higher total blood mercury concentrations, and an increasing number and extent of dental amalgam surfaces. In a parsimonious multivariate linear model when the exposure variable was the number of dental amalgam surfaces (model 2), only smoking, total mercury in blood, and the number of dental amalgam surfaces were significantly associated with log transformed creatinine corrected urine mercury levels. The $\mathrm{R}^{2}$ for model 2 was 0.5204 .

\section{DISCUSSION}

These findings are consistent with previous reports that indicate mercury in urine is significantly associated with an increasing burden of restored amalgam dental surfaces. $.^{20} 2430-34$
Results from our modelling indicate that an estimated increase of $0.7 \mu \mathrm{g} / \mathrm{l}$ in the log transformed values for mercury concentration in urine would occur for every 10 dental surfaces restored with amalgam $(\beta=0.07)$. A similar finding was observed for creatinine corrected urinary mercury concentration $(\beta=0.06)$. Given that women in this study group had approximately nine dental amalgam surfaces $(n=8.7)$, we estimate that dental amalgams contribute approximately $0.6 \mu \mathrm{g} / \mathrm{l}$ to the overall $\log$ transformed urinary mercury concentrations for the average woman in the USA. Kingman and coworkers estimated that an increase of nearly $0.5 \mu \mathrm{g} / \mathrm{l}$ in the log transformed value for total urinary mercury concentration would occur for every 10 surfaces of dental amalgam $(\beta=0.045)$ in men. ${ }^{24}$ On the non-log scale, our findings indicate that for every 10 dental amalgam surfaces, creatinine corrected urinary mercury concentration would increase by $1.8 \mu \mathrm{g} / \mathrm{g}$. For context, we found that $75 \%$ of women in the USA had approximately 12 restored posterior dental surfaces or less, and within this group, the average creatinine corrected urinary mercury concentration was $0.81 \mu \mathrm{g} / \mathrm{g}$ (urine mercury concentration was $1.03 \mu \mathrm{g} / \mathrm{l}$ ) (data not shown).

Our findings suggest that the background urinary mercury concentration for dentate women of reproductive age (that is, urine mercury levels for women with no dental restorations) is $0.69 \mu \mathrm{g} / \mathrm{l}$ in the USA and the geometric mean is $0.35 \mu \mathrm{g} / \mathrm{l}$ (data not shown). This finding is very similar to the estimate reported by Kingman and coworkers for background urinary 
Table 3 The mean number, percent extent, and related standard errors (SE) for dental surfaces by selected characteristics for dentate women aged 16-49 years: United States, 1999-2000

\begin{tabular}{|c|c|c|c|c|c|c|}
\hline Characteristic & $\begin{array}{l}\text { Total posterior } \\
\text { surfaces } \\
\text { Mean (SE) }\end{array}$ & $\begin{array}{l}\text { Restored posterior } \\
\text { surfaces } \\
\text { Mean (SE) }\end{array}$ & $\begin{array}{l}\text { Restored occlusal } \\
\text { surfaces } \\
\text { Mean (SE) }\end{array}$ & $\begin{array}{l}\text { Amalgam } \\
\text { posterior surfaces* } \\
\text { Mean (SE) }\end{array}$ & $\begin{array}{l}\text { Amalgam } \\
\text { occlusal surfaces* } \\
\text { Mean (SE) }\end{array}$ & $\begin{array}{l}\text { Extent of amalgam } \\
\text { surfaces* } \\
\% \text { (SE) }\end{array}$ \\
\hline Total & $71.6(0.49)$ & $12.3(0.66)$ & $5.6(0.23)$ & $8.7(0.38)$ & $4.9(0.19)$ & $12.4(0.51)$ \\
\hline \multicolumn{7}{|l|}{ Age } \\
\hline $35-49$ years & $67.4(0.92)$ & $17.3(1.04)$ & $7.2(0.30)$ & $10.9(0.53)$ & $5.9(0.25)$ & $16.2(0.78)$ \\
\hline $20-34$ years & $74.5(0.55)$ & $8.8(0.55)$ & $4.7(0.25)$ & $7.5(0.42)$ & $4.4(0.23)$ & $10.2(0.55)$ \\
\hline $16-19$ years & $78.0(0.58)$ & $4.9(0.42)$ & $2.9(0.22)$ & $4.4(0.38)$ & $2.7(0.21)$ & $5.7(0.55)$ \\
\hline \multicolumn{7}{|l|}{ Race/ethnicity } \\
\hline Non-Hispanic black & $69.3(0.93)$ & $8.6(0.86)$ & $4.4(0.32)$ & $6.9(0.53)$ & $4.0(0.27)$ & $10.2(0.80)$ \\
\hline Mexican American & $73.5(0.57)$ & $8.7(1.11)$ & $4.3(0.48)$ & $7.0(0.87)$ & $4.0(0.43)$ & $9.9(1.22)$ \\
\hline Non-Hispanic white & $72.6(0.66)$ & $14.0(0.88)$ & $6.2(0.30)$ & $9.6(0.47)$ & $5.3(0.24)$ & $13.4(0.64)$ \\
\hline \multicolumn{7}{|l|}{ Pregnant } \\
\hline Yes & $74.3(1.11)$ & $11.6(1.22)$ & $5.8(0.48)$ & $8.8(0.88)$ & $5.2(0.46)$ & $11.9(1.14)$ \\
\hline No & $71.4(0.53)$ & $12.3(0.66)$ & $5.6(0.23)$ & $8.7(0.38)$ & $4.9(0.19)$ & $12.5(0.52)$ \\
\hline \multicolumn{7}{|l|}{ Educationt } \\
\hline Did not complete high school & $66.1(1.33)$ & $7.7(0.80)$ & $4.1(0.39)$ & $6.6(0.66)$ & $3.9(0.38)$ & $10.3(1.01)$ \\
\hline Completed high school & $68.5(1.11)$ & $12.0(0.91)$ & $5.5(0.34)$ & $9.0(0.65)$ & $4.9(0.31)$ & $13.3(1.00)$ \\
\hline Some college & $73.2(0.60)$ & $15.1(0.97)$ & $6.7(0.32)$ & $10.1(0.51)$ & $5.6(0.26)$ & $14.0(0.65)$ \\
\hline \multicolumn{7}{|l|}{ Cotinine smoking status $\ddagger$} \\
\hline Smoker & $67.3(1.26)$ & $10.0(0.82)$ & $4.8(0.38)$ & $7.6(0.65)$ & $4.3(0.37)$ & $11.7(0.94)$ \\
\hline Non-smoker & $73.0(0.47)$ & $13.3(0.83)$ & $6.0(0.27)$ & $9.2(0.44)$ & $5.2(0.21)$ & $12.9(0.61)$ \\
\hline \multicolumn{7}{|l|}{ Alcohol consumption $\dagger$} \\
\hline Moderate/heavy drinker & $73.8(1.75)$ & $21.1(3.58)$ & $8.2(0.96)$ & $12.3(1.63)$ & $6.5(0.65)$ & $16.4(2.09)$ \\
\hline Light drinker & $72.4(0.77)$ & $12.1(0.93)$ & $5.5(0.30)$ & $8.3(0.47)$ & $4.8(0.24)$ & $11.7(0.65)$ \\
\hline Abstainer & $69.8(0.90)$ & $13.3(0.93)$ & $6.1(0.32)$ & $9.9(0.61)$ & $5.5(0.28)$ & $14.3(0.93)$ \\
\hline \multicolumn{7}{|c|}{$\begin{array}{l}\text { Fish and/or shellfish consumption } \\
\text { in past } 30 \text { days }\end{array}$} \\
\hline $\begin{array}{l}\text { in past } 30 \text { days } \\
\text { Yes }\end{array}$ & $71.7(0.57)$ & $13.2(0.75)$ & $5.9(0.24)$ & $9.1(0.41)$ & $5.1(0.20)$ & $12.9(0.56)$ \\
\hline No & $71.6(1.23)$ & $9.6(0.60)$ & $4.9(0.26)$ & $7.6(0.53)$ & $4.5(0.27)$ & $11.2(0.79)$ \\
\hline \multicolumn{7}{|c|}{ Had a dental visit past 12 months } \\
\hline Yes & $71.7(0.55)$ & $14.0(0.80)$ & $6.3(0.27)$ & $9.7(0.45)$ & $5.4(0.24)$ & $13.8(0.61)$ \\
\hline No & $71.4(1.00)$ & $8.1(0.66)$ & $4.1(0.24)$ & $6.3(0.44)$ & $3.7(0.22)$ & $9.1(0.67)$ \\
\hline $\begin{array}{l}n=1626 . \\
\text { "Derived "amalgam" surfaces. } \\
\text { tlnformation for education and } \\
\ddagger A \text { smoker is defined as having }\end{array}$ & ol available & $20-49$ year old & & & & \\
\hline
\end{tabular}

mercury concentrations in a US military population of mostly white men $($ arithmetic mean $=0.70 \mu \mathrm{g} / \mathrm{l}){ }^{24}$ For background creatinine corrected urinary mercury, the mean concentration for women is $0.50 \mu \mathrm{g} / \mathrm{g}$ and the geometric mean is $0.31 \mu \mathrm{g} / \mathrm{g}$ (data not shown).

Our analysis is unique in that two different analytical approaches were employed during the modelling process that used urine creatinine to correct for urine dilution effects. One standard approach has been to divide urine mercury by urine creatinine to produce a creatinine corrected urinary mercury level. We used this derivation as the dependent variable for regression analyses presented in table 5. In an alternative approach, we used urinary creatinine as an independent variable along with the other covariates of fasting status and lean skeletal muscle mass to adjust for the effects of urinary dilution on mercury levels. The results of these regression analyses produced similar beta coefficients for the dental amalgam exposure covariates. Additionally, urine creatinine levels, leaner skeletal muscle mass, and length of the fast were significantly associated with log transformed urine mercury levels in a parsimonious multivariate linear model (data not shown).

Table 4 Correlations between mercury concentrations and selected characteristics for women aged 16-49 years: United States, $1999-2000$

\begin{tabular}{|c|c|c|c|c|c|c|}
\hline \multirow[b]{2}{*}{ Characteristics } & \multicolumn{3}{|c|}{ Original scale values } & \multicolumn{3}{|l|}{ Log scale values } \\
\hline & $\begin{array}{l}\text { Blood } t \\
\text { R (p value) }\end{array}$ & $\begin{array}{l}\text { Urinef } \\
R \text { ( } p \text { value) }\end{array}$ & $\begin{array}{l}\text { Creatinine } \$ \\
R \text { (p value) }\end{array}$ & $\begin{array}{l}\text { Blood } \\
R \text { ( } p \text { value) }\end{array}$ & $\begin{array}{l}\text { Urine } \\
R \text { ( } p \text { value) }\end{array}$ & $\begin{array}{l}\text { Creatinine } \\
R \text { ( } p \text { value) }\end{array}$ \\
\hline $\begin{array}{l}\text { Age in years } \\
\text { Number of posterior surfaces } \\
\text { Number of restored surfaces } \\
\text { Number of restored occlusal surfaces } \\
\text { Number of amalgam posterior surfaces* } \\
\text { Number of amalgam occlusal surfaces* } \\
\text { Extent of amalgam surfaces* }\end{array}$ & $\begin{array}{l}0.115(<0.001) \\
-0.018(0.470) \\
0.036(0.152) \\
0.056(0.028) \\
0.027(0.293) \\
0.050(0.046) \\
0.027(0.294)\end{array}$ & $\begin{array}{l}0.028(0.267) \\
0.025(0.321) \\
0.262(<0.001) \\
0.317(<0.001) \\
0.340(<0.001) \\
0.329(<0.001) \\
0.321(<0.001)\end{array}$ & $\begin{array}{l}0.166(<0.001) \\
0.057(0.022) \\
0.373(<0.001) \\
0.450(<0.001) \\
0.472(<0.001) \\
0.460(<0.001) \\
0.436(<0.001)\end{array}$ & $\begin{array}{l}0.216(<0.001) \\
0.011(0.645) \\
0.152(<0.001) \\
0.161(<0.001) \\
0.132(<0.001) \\
0.137(<0.001) \\
0.132(<0.001)\end{array}$ & $\begin{array}{l}0.038(0.127) \\
0.085(0.001) \\
0.355(<0.001) \\
0.436(<0.001) \\
0.449(<0.001) \\
0.449(<0.001) \\
0.422(<0.001)\end{array}$ & $\begin{array}{l}0.244(<0.001) \\
0.090(0.001) \\
0.470(<0.001) \\
0.582(<0.001) \\
0.579(<0.001) \\
0.590(<0.001) \\
0.546(<0.001)\end{array}$ \\
\hline \multicolumn{7}{|c|}{$\begin{array}{l}\text { R: weighted Pearson correlation coefficients calculated in SAS. } \\
\text { Urine } \mathrm{Hg} \text { and creatinine adjusted values, } \mathrm{n}=1626 \text {. } \\
\text { Total } \mathrm{Hg} \text { in blood, } \mathrm{n}=1566 \text {. } \\
\text { "Derived "amalgam" surfaces. } \\
\text { †Total mercury in blood ( } \mu \mathrm{g} / \mathrm{l}) \text {. } \\
\text { tUrine mercury }(\mu \mathrm{g} / \mathrm{l}) \text {. } \\
\text { \$Creatinine corrected urine mercury }(\mu \mathrm{g} / \mathrm{g}) \text {. }\end{array}$} \\
\hline
\end{tabular}


Total mercury in blood, an indicator of MeHg exposure, ${ }^{35}$ remained a significant indicator for urine mercury concentrations in the parsimonious models, whereas fish or shellfish consumption did not. The multivariate regression results presented here are consistent with the metabolism of MeHg to $\mathrm{IHg}^{8}$ and suggest that $\mathrm{MeHg}$ exposure from fish consumption contributes to urinary mercury levels. It is also possible that IHg levels due to amalgam exposure are a component of total blood mercury, particularly in women with low fish consumption.

It has been reported that the elimination of mercury from blood following removal of dental amalgam reflects a halflife of approximately 30 days. $^{36}$ In addition to seafood consumption, Vahter and coworkers have reported that IHg in maternal and cord blood and mercury in fetal tissues increases as the number of maternal dental amalgam increases. ${ }^{37}$ Additionally, it has been reported that mercury in breast milk at the time of birth was associated with the number of dental amalgam restorations and fish consumption, but after two months of lactation, only fish consumption remained significant. ${ }^{38}$ Consequently, the speciation of mercury is an important consideration for assessing exposure and evaluating health risks.

While pregnant women have higher plasma volumes and higher globular filtration rates (GFRs), independent effects of pregnancy on urine IHg were not significant during the regression modelling. We also investigated potential effects of moderate/severe renal impairment (GFR $<60$ ), proteinuria, and a very high recent dietary protein intake on urinary mercury levels, and found no relation to urinary mercury concentrations. Although selenium may interact with mercury, ${ }^{39} 40$ serum selenium data was not available to address this issue.

Alcohol is a competitive substrate for the hydrogen peroxide catalase pathway in red blood cells that oxidises inhaled elemental mercury into its divalent inorganic form, which is subsequently excreted in the urine. Although a positive association with alcohol intake and mercury exhalation has been reported, ${ }^{41}$ Kingman and coworkers found a negative association between alcohol consumption and urinary mercury. ${ }^{24}$ Others have reported no association between alcohol and urinary mercury. ${ }^{42}{ }^{43}$ Our findings also suggest a lack of an association, but the relatively low overall consumption of alcohol per person limited our ability to address this issue.

Socioeconomic influences significantly affect the utilisation of dental care. Because poverty/income information was unavailable at the time of this analysis, we used education and dental visit information to mitigate this limitation. Although we were unable to use information on education for persons 16-19 years of age, we did analyse the data for 20-49 year olds and found no significant contribution to the

Table 5 Linear regression results (coefficients (b), standard errors (SE), and $\mathrm{p}$ values) for log transformed urine mercury and creatinine corrected urine mercury concentrations in women aged 16-49 years for selected characteristics: United States, $1999-2000$

\begin{tabular}{|c|c|c|c|c|c|c|c|c|}
\hline \multirow[b]{3}{*}{ Characteristic } & \multicolumn{4}{|c|}{ Log transformed urine mercury concentration } & \multicolumn{4}{|c|}{ Log transformed creatinine corrected urine mercury } \\
\hline & \multicolumn{2}{|c|}{ Unadjusted models } & \multicolumn{2}{|c|}{ Multivariate model* } & \multicolumn{2}{|c|}{ Unadjusted models } & \multicolumn{2}{|c|}{ Multivariate model $\dagger$} \\
\hline & b (SE) & p value & $\overline{b(S E)}$ & p value & $\overline{b \text { (SE) }}$ & p value & b (SE) & p value \\
\hline \multicolumn{9}{|l|}{ Age } \\
\hline $35-49$ years & $0.21(0.10)$ & 0.0464 & $-0.43(0.11)$ & 0.0003 & $0.64(0.10)$ & 0.0000 & \multicolumn{2}{|l|}{ - } \\
\hline $20-34$ years & $0.18(0.08)$ & 0.0290 & $-0.15(0.09)$ & 0.1129 & $0.33(0.09)$ & 0.0005 & & \\
\hline $16-19$ years & \multicolumn{2}{|l|}{ Reference } & \multicolumn{2}{|c|}{ Reference } & \multicolumn{2}{|l|}{ Reference } & \\
\hline \multicolumn{8}{|l|}{ Race/ethnicity } & \\
\hline Non-Hispanic black & $0.42(0.10)$ & 0.0001 & $0.48(0.08)$ & 0.0000 & $-0.10(0.09)$ & 0.2607 & \multirow{3}{*}{\multicolumn{2}{|c|}{ - }} \\
\hline Mexican American & $0.05(0.10)$ & 0.6599 & $0.25(0.06)$ & 0.0003 & $-0.08(0.12)$ & 0.4892 & & \\
\hline Non-Hispanic white & \multicolumn{2}{|l|}{ Reference } & \multicolumn{2}{|l|}{ Reference } & \multicolumn{2}{|l|}{ Reference } & & \\
\hline Pregnant & & & & & & & \\
\hline Yes & $0.07(0.14)$ & 0.6304 & \multirow{2}{*}{\multicolumn{2}{|c|}{ - }} & $0.11(0.10)$ & 0.2428 & \multirow{2}{*}{\multicolumn{2}{|c|}{ - }} \\
\hline No & \multirow{2}{*}{\multicolumn{2}{|c|}{ Reference }} & & & Reference & & & \\
\hline \multicolumn{7}{|l|}{ Educationf } & & \\
\hline Did not complete high school & $-0.12(0.14)$ & 0.3932 & \multirow{3}{*}{\multicolumn{2}{|c|}{ - }} & $-0.32(0.11)$ & 0.0071 & \multirow{3}{*}{\multicolumn{2}{|c|}{-}} \\
\hline Completed high school & \multirow{2}{*}{\multicolumn{2}{|c|}{$\begin{array}{l}-0.1010 .1010 .0753 \\
\text { Reference }\end{array}$}} & & & $-0.22(0.07)$ & 0.0022 & & \\
\hline Some college & & & & & \multirow{2}{*}{\multicolumn{4}{|c|}{ Reference }} \\
\hline Cotinine smoking status $\S$ & & & \multicolumn{2}{|l|}{-} & & & & \\
\hline $\begin{array}{l}\text { Smoker } \\
\text { Non-smoker }\end{array}$ & $\begin{array}{l}-0.33(0.10) \\
\text { Reference }\end{array}$ & 0.0020 & - & & $\begin{array}{l}-0.41(0.09) \\
\text { Reference }\end{array}$ & 0.0000 & $-0.20(0.05)$ & 5) 0.0004 \\
\hline Had a dental visit past 12 months & & & & & & & & \\
\hline Yes & $0.12(0.08)$ & 0.1263 & - & & $0.27(0.07)$ & 0.0005 & - & \\
\hline No & Reference & & & & Reference & & & \\
\hline $\begin{array}{l}\text { Fish and/or shellfish consumption in } \\
\text { past } 30 \text { days }\end{array}$ & & & & & & & & \\
\hline Yes & $0.40(0.09)$ & 0.0000 & - & & $0.47(0.08)$ & 0.0000 & - & \\
\hline No & Reference & & & & Reference & & & \\
\hline Alcohol consumption $\ddagger$ & & & & & & & & \\
\hline Moderate/heavy drinker & $-0.07(0.22)$ & 0.7299 & & & $0.14(0.17)$ & 0.4051 & - & \\
\hline Light drinker & $-0.18(0.09)$ & 0.0577 & - & & $-0.07(0.09)$ & 0.4326 & & \\
\hline Abstainer & Reference & & & & Reference & & & \\
\hline Total blood mercury concentration & $0.35(0.04)$ & 0.0000 & $0.30(0.04)$ & 0.0000 & $0.41(0.03)$ & 0.0000 & $0.35(0.02)$ & 0.0000 \\
\hline Number of amalgam surfaces $\S$ & $0.06(0.01)$ & 0.0000 & $0.07(0.01)$ & 0.0000 & $0.07(0.00)$ & 0.0000 & $0.06(0.00)$ & 0.0000 \\
\hline$R^{2}$ & NA & & 0.3183 & & NA & & 0.5204 & \\
\hline $\begin{array}{l}\text { NA, not applicable. } \\
\text {-, indicates that the covariate was no } \\
\text { *Model 1: most parsimonious model } \\
\text { † Model 2: most parsimonious model } \\
\text { flnformation for education and alcoh } \\
\text { \$A smoker is defined as having a cot } \\
\text {-Used as a continuous variable. Log }\end{array}$ & $\begin{array}{l}\text { cluded in the mo } \\
\text { en dependent va } \\
\text { en dependent vo } \\
\text { available only on } \\
\text { e level of } 10 \mathrm{ng} \\
\text { nsformed value } f\end{array}$ & $\begin{array}{l}\text { odel. } \\
\text { riable is } \\
\text { ariable is } \\
20-49 \\
\mathrm{~g} / \mathrm{ml} \text { or hi } \\
\text { or total b }\end{array}$ & $\begin{array}{l}\text { nsformed uri } \\
\text { nsformed cre } \\
\text { lds. These co } \\
\text { nercury. }\end{array}$ & $\begin{array}{l}\text { mercu } \\
\text { tinine } c \\
\text { riates v }\end{array}$ & $\begin{array}{l}\text { /l). } \\
\text { ed urine mercu } \\
\text { ot included in }\end{array}$ & $\begin{array}{l}(\mu \mathrm{g} / \mathrm{g}) . \\
\text { multivari }\end{array}$ & egression analy & lyses. \\
\hline
\end{tabular}


study outcomes. Occupational exposure to mercury could be a potential confounder for our study. The detailed occupation data for NHANES 1999-2000 NHANES was not available for analysis. As a practical matter, large numbers of women in this age range are home makers, and have never been employed. Further, as a nationally representative sample, the frequency of persons employed in mercury exposed occupations in NHANES (that is, certain manufacturing jobs, dental workers, etc) is comparatively small. Also, we found no relation between general employment status and urinary mercury concentrations.

Although very small amounts of mercury are known to occur in tobacco products, ${ }^{44-46}$ our final regression models indicated a significant inverse association between smoking and urinary mercury levels. We do not have an explanation for this finding. We believe it is potentially due to an unidentified confounder, such as dental health care behaviour, rather than representing a true biological effect.

There are additional study limitations. Our cross-sectional design does not permit definitive evaluation of causality or temporal relations. Because we used posterior dental restorations as a surrogate for amalgam fillings, misclassification of exposure may have affected our findings. We minimised this bias by discounting any restored surface area indicative of a fabricated dental crown. Additionally, some of the dental surfaces could have been restored with non-amalgam materials; however, this misclassification error most likely would have underestimated the magnitude of the association between urinary mercury and dental amalgams. Although we cannot quantitate this error, it is notable that our findings are similar to the Kingman et al study which used actual clinical information on amalgam restorations. The strength of this study is its use of a nationally representative sample not selected by multiple risk indicators or other potentially confounding factors.

This is the first study to evaluate the relation between dental restorations and mercury concentrations in a nationally representative sample in the United States. Our findings show that among women in the USA increasing mercury levels in urine are associated with increased numbers of dental amalgam surfaces. Although our findings do not address the important issues of adverse health effects at low thresholds of mercury exposure, they do provide important reference data that should contribute significantly to the ongoing scientific and public health policy debate on the use of dental amalgams in the USA.

\section{ACKNOWLEDGEMENTS}

The authors wish to acknowledge the contributions made by Margaret Carroll for providing statistical support and interpretation, and by Dr David Lacher for providing laboratory data quality evaluation and interpretation. Both are employed by the Centers for Disease Control and Prevention/National Center for Health Statistics.

The authors also wish to acknowledge Dr William Kohn for reviewing and providing comments to this manuscript. Dr Kohn is employed by Centers for Disease Control and Prevention/National Center Chronic Disease Prevention and Health Promotion/Division of Oral Health.

This study was sponsored by the Centers for Disease Control and Prevention. Additional funding for the oral health examination was provided by the National Institute for Dental and Craniofacial Research.

\section{Authors' affiliations}

B A Dye, S E Schober, C F Dillon, M McDowell, Centers for Disease Control and Prevention/National Center for Health Statistics, Hyattsville, $M D$, USA

R L Jones, T H Sinks, Centers for Disease Control and Prevention/ National Center for Environmental Health, Atlanta, GA, USA

C Fryar, Harris Orkand Information Services, Falls Church, VA, USA

\section{Competing interests: none}

Ethics statement: All study participants gave informed consent in accordance with the Institutional Review Board and study ethic guidelines at the Centers for Disease Control and Prevention.

The authors were bona fida officers or employees of the US Government at the time the manuscript was prepared, the manuscript is a "United States Government Work" as described in the US Copyright Act, and the manuscript was written as part of the author's official duties as a US Government employee. As such, the manuscript is not subject to copyright protection.

As federal employees of the Centers for Disease Control and Prevention, we are following the mission of the National Center for Health Statistics to collect, analyse, and release information of public health importance. Other US government or research agencies often use this information to initiate the next step forward towards proposing or implementing policy recommendations. Consequently, we believe that it is not appropriate for us to detail potential policy implications or make policy recommendations in this paper.

\section{APPENDIX}

The standard deviation of the mean is calculated by applying the formula,

$$
\operatorname{Std}_{\mathrm{cs}}=\sqrt{\operatorname{Std}_{\mathrm{srs}}^{2}+\mathrm{sem}_{\mathrm{cs}}^{2}}
$$

where $\operatorname{Std}_{\text {srs }}$ is the standard deviation of the variable which can be obtained through SAS PROC means or univariate, and $\mathrm{sem}_{\mathrm{CS}}$ is the standard error of the mean estimated by means of the delete 1 jackknife method. This transformation is applied to account for the complex sample design to obtain a design based estimate of the standard deviation.

The standard deviation of the geometric mean is first calculated on the log scale by applying the formula,

$$
\operatorname{Std}_{\mathrm{cs}}=\sqrt{\mathrm{Std}_{\mathrm{srs}}^{2}+\mathrm{sem}_{\mathrm{cs}}^{2}}
$$

where $\operatorname{Std}_{\text {srs }}$ is the standard deviation of the log transformed variable which can be obtained through SAS PROC means or univariate and $\operatorname{sem}_{\mathrm{cs}}$ is the standard error of the mean estimated by means of the delete 1 jackknife method. This transformation is applied to account for the complex sample design to obtain a design based estimate of the standard deviation and is then back transformed to obtain the desired result.

\section{REFERENCES}

1 US Department of Health and Human Services, Public Health Service. Dental amalgam: a scientific review and recommended Public Health strategy for research, education, and regulation. Washington, DC: DHHS, PHS, 1993.

2 Corbin SB, Kohn WG. The benefits and risks of dental amalgam: current findings. J Am Dent Assoc 1994;125:381-8.

3 Anon. Dental amalgam: update on safety concerns. ADA council on Scientific Affairs. J Am Dent Assoc 1998;129:494-503.

4 US Food and Drug Administration. FDA Docket No. 03N-0169. http:// www.fda.gov/OHRMS/DOCKETS/98fr/03-11648.html, 2003 (accessed 27 May 2003).

5 Clarkson TW, Magos L, Myers GJ. The toxicology of mercury-current exposures and clinical manifestations. N Engl J Med 2003;349:1731-7.

6 World Health Organisation (WHO). Environmental Health Criteria 118. Inorganic mercury. Geneva: World Health Organisation, 1991.

7 World Health Organisation. Mercury. In: Air quality guidelines, 2nd edn. Copenhagen, Regional Office for Europe, 2000 (http://www.who.dk/air/ Activities/20020620_1).

8 National Academy of Sciences. Toxicological effects of methyl mercury. Washington, DC: National Research Council, 2000.

9 Centers for Disease Control and Prevention, Agency for Toxic Substances and Disease Registry (ATSDR). Public health statement for mercury, 1999. http://www.atsdr.coc.gov/toxprofiles/phs46.html (accessed 22 December 2003).

10 Clarkson TW. Mercury. Ann Rev Public Health 1983;4:375-80.

11 Miettinen JK. Absorption and elimination of dietary $\mathrm{Hg}^{++}$and methyl mercury in man. In: Miller MW, Clarkson TW, eds. Mercury, mercurial, and mercaptans. Springfield, IL: CC Thomas, 1973:233-46. 
12 Vimy MJ, Lorscheider FL. Intra-oral air mercury released from dental amalgam. J Dent Res 1985;64:1069-71.

13 Bjorkman L, Lind B. Factors influencing mercury evaporation rate from dental amalgam fillings. Scand J Dent Res 1992;100:354-60.

14 Sallsten G, Thoren J, Barregard L, et al. Long-term use of nicotine chewing gum and mercury exposure from dental amalgam fillings. J Dent Res 1996;75:594-8.

15 Isacsson G, Barregard L, Selden A, et al. Impact of nocturnal bruxism on mercury uptake from dental amalgams. Eur J Oral Sci 1997;105:251-7.

16 Robertello FJ, Dishman MV, Sarrett DC, et al. Effect of home bleaching products on mercury release from an admixed amalgam. Am J Dent 1999; 12:227-30.

17 Rotstein I, Dogan H, Avron Y, et al. Mercury release from dental amalgam after treatment with 10\% carbamide peroxide in vitro. Oral Surg Oral Med Oral Pathol 2000;89:216-19.

18 Nylander M, Friberg L, Lind B. Mercury concentrations in the human brain and kidneys in relation to exposure from dental amalgam fillings. Swed Dent J 1987;11:179-87.

19 Clarkson TW, Friberg L, Hursh JB, et al. The prediction of intake of mercury vapor from amalgams. In: Clarkson TW, Friberg L, Nordberg GF, Sager PR eds. Biological monitoring of toxic metals. New York: Plenum Press, 1988.

20 Skare I, Engqvist A. Human exposure to mercury and silver released from dental amalgam restorations. Arch Environ Health 1994;49:384-94.

21 Halbach S, Kremers L, Willruth $\mathrm{H}$, et al. Systemic transfer of mercury from amalgam fillings before and after cessation of emission. Environ Res 1998;77:1 15-23.

22 Engqvist A, Colmsjo A, Skare I. Speciation of mercury excreted in feces from individuals with amalgam fillings. Arch Environ Health 1998;53:205-13.

23 Sandborgh-Englund G, Elinder CG, Johanson G, et al. The absorption, blood levels, and excretion of mercury after a single dose of mercury vapor in humans. Toxicol Appl Pharmacol 1998;150:146-53.

24 Kingman A, Albertini T, Brown $\sqcup$. Mercury concentrations in urine and whole blood associated with amalgam exposure in a US military population. J Dent Res 1998;77:461-71.

25 Centers for Disease Control and Prevention, National Center for Environmental Health (NCEH), Division of Laboratory Sciences, Inorganic Toxicology and Nutrition Branch. Laboratory procedure manual: urine mercury, August, 2001.

26 Schober SE, Sinks TH, Jones RL, et al. Blood mercury levels in US children and women of childbearing age, 1999-2000. JAMA 2003;289:1667-74.

27 Dufour MC. What is moderate drinking? Defining "drinks" and drinking levels. Alcohol Research and Health 1999;23:5-14.

28 Lee RC, Wang Z, Heo M, et al. Total-body skeletal muscle mass: development and cross-validation of anthropometric prediction models. Am J Clin Nutr 2000;72:796-803.

29 Beckman Instruments. Beckman Synchron CX3 clinical system, operating and services instruction. Beckman Instruments, Inc., 200 South Kraemer Blvd, Brea, CA 92621, 2000.
30 Olstad ML, Holland RI, Wandel N, et al. Correlation between amalgam restorations and mercury concentrations in urine. J Dent Res 1987;66: 1179-82.

31 Begerow J, Zander D, Freier I, et al. Long-term mercury excretion in urine after removal of amalgam fillings. Int Arch Occup Environ Health 1994;66:209-12.

32 Halbach S, Kremers L, Willruth $\mathrm{H}$, et al. Compartmental transfer of mercury released from amalgam. Hum Exp Toxicol 1997;16:667-72.

33 Berglund A. Estimation by a 24 -hour study of the daily dose of intra-oral mercury vapor inhaled after release from dental amalgam. J Dent Res 1990;70:233-7.

34 Soleo $L$, Elia $G$, Apostoli $P$, et al. The influence of amalgam filling on urinary mercury excretion in subjects from Apulia (Southern Italy). G Ital Med Lav Erg 1998;20:75-81.

35 US Environmental Protection Agency. Mercury Study Report to Congress, Vol I, Executive Summary. Pub No. EPA-452/R-97-003. Washington: EPA, 1997.

36 Snapp KR, Boyer DB, Peterson LC, et al. The contribution of dental amalgam to mercury in blood. J Dent Res 1989;68:780-5.

37 Vahter M, Akesson A, Lind B, et al. Longitudinal study of methylmercury and inorganic mercury in blood and urine of pregnant and lactating women as well as in umbilical cord blood. Environ Res 2000;84:186-94.

38 Drexler $\mathbf{H}$, Schaller $\mathrm{KH}$. The mercury concentration in breast milk resulting from amalgam fillings and dietary habits. Environ Res 1998;77:124-9.

39 Goyer RA. Toxic and essential metal interactions. Annu Rev Nutr 1997; 17:37-50.

40 Seppanen K, Kantola M, Laatikainen K, et al. Effect of supplementation with organic selenium on mercury status as measured by mercury in pubic hair. J Trace Elem Med Biol 2000;14:84-7.

41 Sallsten G, Kreku S, Unosson H. A small dose of ethanol increases the exhalation of mercury in low-level-exposed humans. J Toxicol Environ Health Part A 2000;60:89-100.

42 Echeverria D, Heyer NJ, Martin MD, et al. Behavioral effects of low-level exposure to elemental $\mathrm{Hg}$ among dentists. Neurotoxicol Teratol 1995; 17:161-8.

43 Langworth S, Elinder CG, Göthe CJ, et al. Biological monitoring of environmental and occupational exposure to mercury. Int Arch Occup Environ Health 1991;63:161-7.

44 Andren AW, Harriss RC. Mercury content of tobaccos. Environ Lett 1971;1:231-4.

45 Suzuki T, Shishido S, Urushiyama K. Mercury in cigarettes. Tohoku J Exp Med 1976;119:353-6.

46 G, Zhang $\mathrm{C}, \mathrm{Hu} \mathrm{O}$, et al. Simultaneous determination of four heavy metal ions in tobacco and tobacco additive by online enrichment followed by RP-HPLC and microwave digestion. J Chromatogr Sci 2001;39:195-9. 